\title{
PEMBUATAN APLIKASI SIMULASI TRAINING PICKING PROCESS DI WAREHOUSE PT. SCHNEIDER ELECTRIC MANUFACTURING BATAM
}

\author{
Elisa Margareth Sihombing*, Nur Cahyono Kushardianto**, Fadli Hamsani**, Yogi Ilhami** \\ * Informatics Engineering, Batam State Polytechnic \\ ** Multimedia and Network Engineering, Batam State Polytechnic \\ *** Schneider Electric Manufcturing Batam
}

\begin{tabular}{l} 
Article Info \\
Article history: \\
Received Jun $12^{\text {th }}, 2020$ \\
Revised Jul $10^{\text {th }}, 2020$ \\
Accepted Jul $16^{\text {th }}, 2020$ \\
\hline
\end{tabular}

Keyword:

Game

Simulasi

Augmented Reality

Warehouse

Single Marker

\begin{abstract}
ABSTRAK
Warehouse merupakan tempat penyimpanan barang produksi ataupun hasil dari produksi yang dimana dalam rentang waktu tertentu akan di distribusikan sesuai dengan permintaan. Salah satu pekerjaaan di bagian ini adalah sebagai seorang picker. Kondisi warehouse yang luas membuat picker kesulitan dalam melakukan pekerjaannya. Game simulasi merupakan salah satu cara melakukan simulasi perkerjaan yang menjadi lebih menarik dan menyenangkan. Game simulasi dan training merupakan salah satu jenis game yang sedang berkembang dengan pesat di berbagai bidang termasuk dalam bidang industri, maka pada pelaksanaan Tugas Akhir ini akan melakukan pembuatan Aplikasi Warehouse Picking Process di PT. Schneider Electric Manufacturing Batam berbasis game. Dalam aplikasi simulasi dapat dipadukan dengan teknologi baru seperti teknologi realitas tertambah atau yang biasa disebut dengan Augmented Reality (AR). Dalam pembuatan aplikasi ini menggunakan teknologi Augmented Reality dalam melakukan simulasi pengambilan item di warehouse agar meminimalisir terjadinya kesalahan dan merugikan perusahaan serta melatih kecepatan dan ketepatan seorang picker.
\end{abstract}

Copyright $\left({ }_{0} 2019\right.$ Institute of Advanced Engineering and Science. All rights reserved.

\section{Corresponding Author:}

Third Author,

Departement of Electrical and Computer Engineering,

National Chung Cheng University,

168 University Road, Minhsiung Township, Chiayi County 62102, Taiwan, ROC.

Email: 1sntl@ccu.edu.tw

\section{PENDAHULUAN}

Warehouse atau yang biasa disebut gudang merupakan tempat penyimpanan barang produksi ataupun hasil dari produksi yang dimana dalam rentang waktu tertentu akan di distribusikan ke tempat yang dituju sesuai denga permintaan. Salah satu pekerjaaan di bagian warehouse atau pergudangan adalah sebagai seorang picker. Picker merupakan posisi yang paling dipentingkan didalam suatu warehouse, sebab perkerjaan yang dilakukan oleh seorang picker adalah melakukan pencarian barang-barang yang telah dipesan dan siap untuk didistribusikan. Picker tidak berkomunikasi dengan konsumen secara langsung, namun ia berkomunikasi dengan lokasi barang. Lokasi warehouse yang cukup luas menjadi titik kesulitan seorang karyawan baru di bagian picker dalam melakukan pekerjaannya.

Game simulasi merupakan salah satu cara melakukan simulasi perkerjaan yang menjadi lebih menarik dan seru. Tujuan game simulasi ini agar simulasi lebih menarik dan pemain mendapatkan ilmu yang berasal dari game tentang kegiatan yang ada didunia nyata serta meminimalisir kesalalahan secara langsung. Dalam game simulasi dapat dipadukan dengan teknologi baru seperti teknologi realitas tertambah atau yang biasa disebut dengan Augmented Reality (AR). Teknologi ini merupakan teknologi yang dimana objek 2D maupun 3D maya berada dalam dunia nyata dan dalam waktu yang nyata[1]. 
Sebagai salah salah satu perusahaan industri yang memiliki warehouse yang cukup besar, PT. Schneider Electric Manufacturing Batam membutuhkan game simulasi dan training untuk karyawan di bagian warehouse. Berdasarkan permasalahan yang ada, penulis berniat untuk mengembangkan game simulasi dan berbasis Augmented Reality agar dapat mempermudah suatu perusahaan dalam melakukan simulasi di warehouse pada karyawannya agar informasi atau arahan yang ingin di sampaikan dapat diterima dengan jelas dan mudah untuk dimengerti karena di kemas dalam bentuk permainan yang seru demi meminimalisir kesalahan penyampaian atau penerimaan informasi, serta meminimalisir kerugian perusahaan. Bukan hanya itu, permainan ini juga dapat digunakan untuk para karyawan perusahaan tersebut menjadi permainan hiburan untuk menambah kecepatan dan ketepatan pekerja.

\section{LANDASAN TEORI}

A. Game simulasi

Permainan simulasi merupakan game yang dikembangkan untuk mengasumsikan peran khusus yang bertindak seolaholah pengguna terlibat langsung dalam situasi nyata dan berkompetensi dala, mencapai tujuan dari game. Dengan adanya game simulasi, pemain lebih terlatih ketika terlibat langsung pada situasi nyata[2].

B. Metode single marker

Metode single marker adalah metode yang menggunakan kamera untuk melakukan tracking objek yang di tangkap hanya satu[3]. Ketika kamera smartphone men-scan satu marker maka di dalam layar smartphone akan muncul objek maya 2D maupun 3D. Sedangkan dibandingkan metode multi marker memiliki perbedaan dimana metode ini merupakan metode yang mana kamera smartphone melakukan tracking objek yang di tangkap lebih dari satu.

\section{Vuforia Qualcom}

Vuforia Qualcom merupakan Augmented Reality Software Development untuk perangkat bergerak dalam mempermudah pembuatan aplikasi Augmented Reality. Pada Vuforia menggunakan teknologi computer vision dalam mengenali dan melacak marker atau image target seta objek 3D sederhana, seperti kotak, secara real-time[3]. Vuforia menyediaakan online target management system yang dimana pengguna dapat mengunggah image target yang akan digunakan dan membuatnya menjadi suatu database.

\section{QR code}

QR Code (Quick Response Code) merupakan barcode dua dimensi yang dengan mudah di baca oleh smartphone. Dalam QR Code memungkinkan dalam mengkodekan lebih dari 4000 karakter dalam 1 kode batang 2 dimensi. QR Code dapat dipergunakan untuk menampilakn teks kepada user, membuka alamat url, serta menulis pesan teks[4].

\section{E. Skala likert}

Skala Likert adalah metode skala bipolar dalam mengukur respon positif maupun negative terhadap suatu pernyataan. Pada skala likert digunakan empat skala pilihan yang digunakan dalam kuesioner. Kuesioner yang diberikan kepada responden terdapat 4 pilihan jawaban yang dapat dipilih, antara lain sangat setuju, setuju, tidak setuju, dan sangat tidak setuju[5].

\section{METODE PENELITIAN}

Metode penelitian dalam pembuatan aplikasi simulasi training picking process di warehouse PT. Schneider Electric Manufacturing Batam menggunakan Game Development Life Cycle yang memiliki 6 tahapan yaitu initiation, pre-production, production, testing, beta, release.[6]

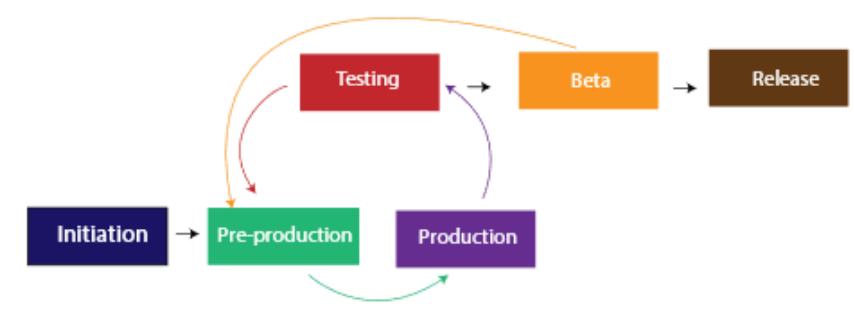

Gambar 1. Game Development Life Cycle (GDLC) Diagram

Dalam initiation, pembuatan aplikasi bertujuan untuk menciptaka media training bagi operator baru untuk melatih dalam melakukan proses picking di warehouse dengan cara yang lebih interaktif. 
Proses pre-production, dirancang flowchart, gameplay, scriptwritting, serta storyboard yang sedemikian mirip dengan proses picking yang ada di warehouse PT. Schneider Electric Manufacturing Batam. Selanjutnya mendesain tampilan antarmuka aplikasi dengan menggunakan Adobe Illustrator CS6.

Proses production dilakukan pembuatan asset 3D dari rak dan item yang akan digunakan menggunakan blender, lalu export 3D kedalam format .fbx. Tahap selanjutnya pembuatan database marker QR code menggunakan vuforia Qualcom. Dalam Unity 3D, dilakukan pembuatan aplikasi untuk simulasi yang berbasis augmented reality dan di export dalam format .apk atau untuk platform android.

Testing menggunakan pengujian black box untuk memastika aplikasi dapat digunakan secara fungsional tanpa ada terjadi eror[7]. Proses testing dilakukan oleh tim digital transformation PT. Schneider Electric Manufacturing Batam.

Beta, dalam tahap ini menggunakan metode User Acceptance Test (UAT) untuk menguji aplikasi yang telah dibuat telah dapat diterima pengguna atau tidak[8]. Dalam metode ini menggunakan kuesioner yang akan disebar ke 30 responden di PT. Schneider Electric Manufacturing Batam untuk memberi respon dari 9 pernyataan. Jawaban dari responden akan dihitung menggunakan Skala Likert. Berikut merupakan 4 pilihan jawaban dengan bobot skor sebagai berikut:

Tabel 1. Bobot Pasca Produksi

\begin{tabular}{|c|c|}
\hline Jawaban & Skor positif \\
\hline Sangat setuju & 5 \\
\hline Setuju & 4 \\
\hline Tidak Setuju & 2 \\
\hline Sangat tidak setuju & 1 \\
\hline
\end{tabular}

Untuk mendapatkan persentase tanggapan responden, menggunakan rumus persamaan skala likert sebagai berikut:

$$
\text { Skor setiap jawaban }=\text { Jumlah responden } \times \text { Skor jawaban }
$$

Setelah didapatkan hasil skor tertinggi maka akan dilanjutkan dengan menentukan hasil dalam bentuk \% dengan rumus sebagai berikut:

$$
\text { Persentase }(P)=\frac{\text { Total Skor Seluruh Jawaban }(f)}{\text { Skor Tertinggi }(n)} \times 100
$$

Dengan index persentase interval penilaian sebagai berikut:

Tabel 2. Bobot Pasca Produksi

\begin{tabular}{|c|c|}
\hline Interva; & Keterangan \\
\hline $0 \%-24,99 \%$ & Sangat setuju \\
\hline $25 \%-49,99 \%$ & Setuju \\
\hline $50 \%-74,99 \%$ & Tidak Setuju \\
\hline $75 \%-100 \%$ & Sangat tidak setuju \\
\hline
\end{tabular}

Dari hasil perhitungan, akan diketahui apakah aplikasi simulasi training picking process telah memenuhi permintaan PT. Schneider Electric Manufacturing Batam.

Dalam release, aplikasi simulasi ini akan disimpan pada google draive dan smartphone android untuk melakukan proses simulasi bagi karyawan di PT. Schneider Electric Manufacturing Batam

\section{HASIL DAN ANALISIS}

Setelah proses pembuatan selesai, tahap selanjutnya adalah impementasi, testing produk, dan proses analisis dari respon pengguna terhadap aplikasi.

\subsection{Implementasi}

Berikut merupakan implementasi dari aplikasi simulasi training picking process di warehouse PT. Schneider Electric Manufacturing Batam: 
1. Main menu

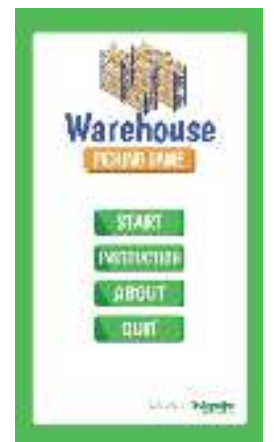

Gambar 2. Scene main menu

Dalam scene main menu terdapat 4 button yaitu button Start untuk memulai simulasi training. Introduction untuk menampilkan cara dalam melakukan simulasi, about yang berisi informasi umum mengenai simulasi dan terakhir quit.

2. Start

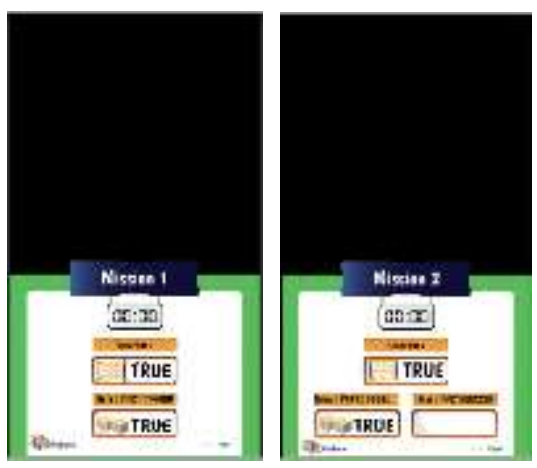

Gambar 3. Scene Start

Dalam scene start terdapat 2 misi yang harus diselesaikan oleh user. Misi pertama memiliki tugas mencari 1 lokasi rak dan 1 item. Jika lokasi dan item benar, maka akan muncul AR dari rak dan item ketika QR code di scan. Hasil akhir dari misi akan muncul timer yang diperoleh dari user dalam menyelesaikan misi.

3. Instruction

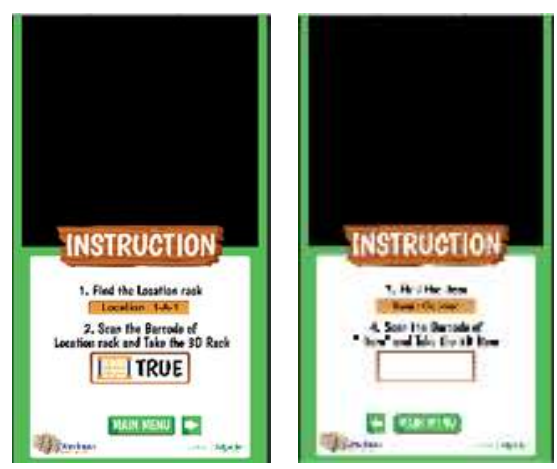

Gambar 4. Scene Instruction

Dalam scene instruction menampilkan cara dalam melakukan simulasi. 
4. About

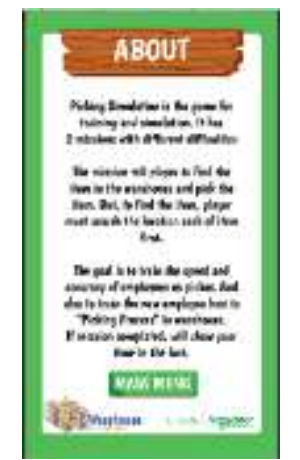

Gambar 5. Scene About

Dalam scene about berisi informasi singkat mengenai simulasi training picking process di warehouse PT. Schneider Electric Manufacturing Batam.

\subsection{Pengujian beta dan analisis}

Setelah hasil kuesioner elah terkumpul, maka kuesioner akan di di proses menggunakan perhitungan skala likert. Responden merupakan operator di warehouse PT. Schneider Electric Manufacturing Batam dengan jumlah responden 30 orang.

\begin{tabular}{|c|c|c|c|c|c|}
\hline \multicolumn{6}{|c|}{$\begin{array}{l}\text { Jumlah responden: } 20 \\
\text { Perusahaan: PT. Schneider Electric Manufacturing Batam } \\
\text { Jabatan: Operator warehouse }\end{array}$} \\
\hline No. & Pernyataan & $\begin{array}{l}\text { Sangat } \\
\text { Setuju }\end{array}$ & Setuju & $\begin{array}{l}\text { Tidak } \\
\text { Setuju }\end{array}$ & $\begin{array}{l}\text { Sangat } \\
\text { Tidak } \\
\text { Setuju }\end{array}$ \\
\hline \multicolumn{6}{|c|}{ USEFULNESS } \\
\hline 1 & $\begin{array}{l}\text { Aplikasi ini membantu saya lebih } \\
\text { efektif dalam memahami proses } \\
\text { picking }\end{array}$ & 18 & 12 & 0 & 0 \\
\hline 2 & $\begin{array}{l}\text { Aplikasi ini sesuai dengan kebutuhan } \\
\text { training }\end{array}$ & 14 & 16 & 0 & 0 \\
\hline \multicolumn{6}{|c|}{ EASE OF USE } \\
\hline 3 & Aplikasi mudah digunakan & 19 & 11 & 0 & 0 \\
\hline 4 & $\begin{array}{l}\text { Langkah penggunaan aplikasi sangat } \\
\text { mudah dan sederhana }\end{array}$ & 16 & 14 & 0 & 0 \\
\hline 5 & $\begin{array}{l}\text { Tampilan Aplikasi Simulasi Training } \\
\text { jelas dan menarik }\end{array}$ & 13 & 17 & 0 & 0 \\
\hline \multicolumn{6}{|c|}{ EASE OF LEARNING } \\
\hline 6 & $\begin{array}{l}\text { Saya memahami penggunaan aplikasi } \\
\text { ini dengan cepat }\end{array}$ & 15 & 13 & 2 & 0 \\
\hline 7 & $\begin{array}{l}\text { Proses picking yang dilakukan pada } \\
\text { aplikasi simulasi dan nyata sesuai }\end{array}$ & 8 & 21 & 1 & 0 \\
\hline \multicolumn{6}{|c|}{ SATISFACTION } \\
\hline 8 & $\begin{array}{lll}\text { Penggunaan } & \text { aplikasi } & \text { ini } \\
\text { menyenangkan } & & \end{array}$ & 13 & 17 & 0 & 0 \\
\hline 9 & $\begin{array}{l}\text { Saya merasa puas dengan kinerja } \\
\text { aplikasi ini }\end{array}$ & 14 & 15 & 1 & 0 \\
\hline
\end{tabular}

Dari hasil koesioner keseluruhan, hasil dari User Acceptance Test dapat disajikan dengan grafik sebagai berikut: 


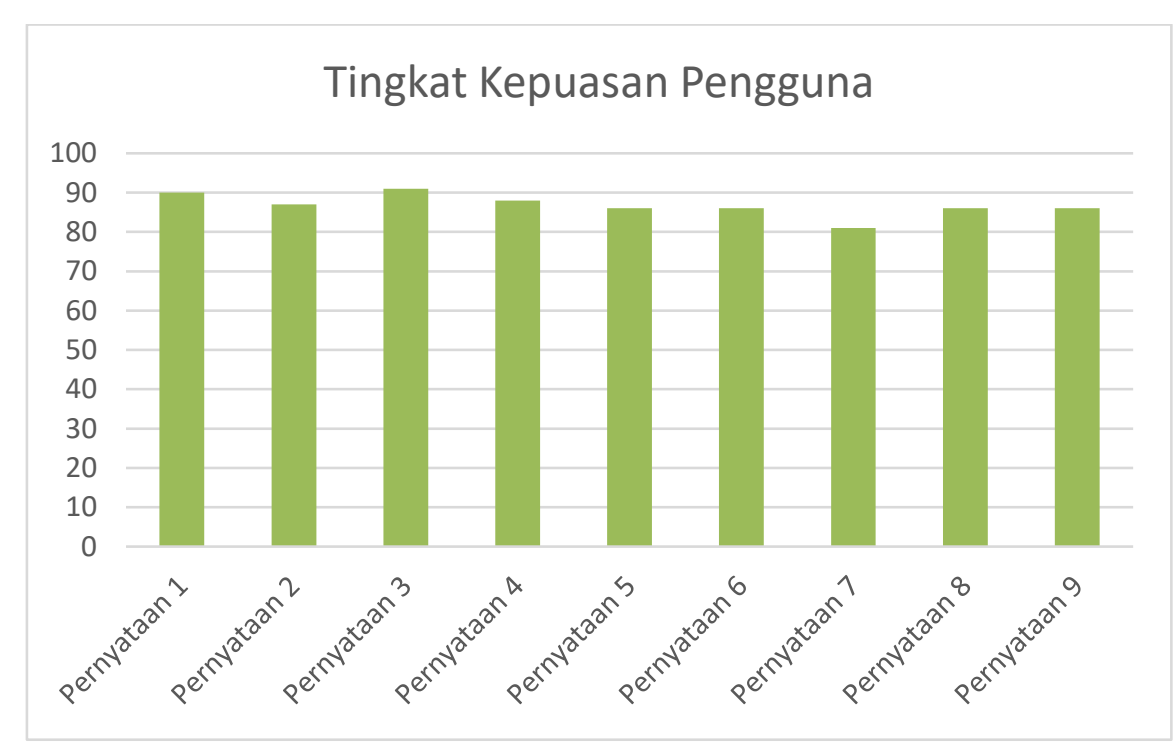

Gambar 6. Grafik tingkat kepuasan pengguna

Jika mengacu pada grafik diatas, dalam pembuatan Aplikasi Simulasi Training Picking Process memperoleh hasil diatas $80 \%$ di setiap pernyataan dan dari semua analisa di total dan di cari nilai rata-rata persentase maka didapatkan bahwa keberhasilan aplikasi ini dengan nilai 86,77\% atau 87\% jika dibulatkan ini menandakan bahwa pengguna sudah sangat setuju dengan kegunaan dari Aplikasi Simulasi Training Picking Process.

\section{KESIMPULAN}

Aplikasi Simulasi Picking Process telah berhasil dibuat dengan menggunakan metode Game Development Life Cycle yang menghasilkan aplikasi simulasi training berbasis Augmented Reality. Mengimplementasikan Augmented Reality untuk simulasi training dilakukan dengan cara melakukan pengujian dan selanjutnya dilakukan perhitungan dengan skala likert. Hasil perhitungan dengan metode skala likert menunjukkan $86,77 \%$ untuk hasil presentase akhir. Dari hasil tersebut dapat disimpulkan bahwa pengguna sudah sangat setuju dengan aplikasi tersebut.

\section{ACKNOWLEDGEMENTS}

Penulis mengucapkan terima kasih kepada PT. Schneider Electric Manufacturing Batam, karyawan terkhusus kepada tim Digital Transformation, Pak Fadli Hamsani, Su Wen, Kak Desanti yang memberikan informasi dan membimbing selama proses pembuatan aplikasi. Penulis juga mengucapkan terima kasih kepada Pak Nur Cahyono Kushardianto sebagai dosen pembimbing Politeknik Negeri Batam yang telah membimbing selama penelitian ini.

\section{DAFTAR PUSTAKA}

[1] Haryani, Prita, \& Joko Triyono, 2017, Augmented Reality (Ar) Sebagai Teknologi Interaktif Dalam Pengenalan Benda Cagar Budaya Kepada Masyarakat. Simetris, 2, 8, 807-812

[2] Fitratunnany Insanittaqwa, Vika, Kuswardayan, Imam dan Sunaryono, Dwi, 2014, Game Edukasi 'Simulasi Haji' Menggunakan Ren'Py pada Perangkat Android untuk Simulasi Perjalanan Ibadah Haji, Simetris. Jurnal Teknik Pomits, 3, 1, 52-57

[3] Nugroho, Atmoko, dan Basworo A.P, 2017, Aplikasi Mobile Augmented Reality Berbasis Vuforia Dan Unity Pada Pengenalan Objek 3d Dengan Studi Kasus Gedung M Universitas Semarang. Transformatika, 2, 14, 86-91

[4] Tri Widayati, Yohana, 2017, Aplikasi Teknologi Qr ( Quick Response ) Code Implementasi Yang Universal, KOMPUTAKI, 3, 1, 65-82

[5] Budiaji, W. (2013). Skala Pengukuran Dan Jumlah Respon Skala Likert. Jurnal Ilmu Pertanian dan Perikanan, 2, 127-133.

[6] Ramadan R, Widyani Y. (2013). Game Development Life Cycle Guidelines. https://www.researchgate.net/publication/271548605_Game_development_life_cycle_guidelines. Dipublikasi 2013. Diakses 2 Desember 2018

[7] Mustaqbal, dkk. 2016. Pengujian Aplikasi Menggunakan Black Box Testing Boundary Value Analysis (Studi Kasus : Aplikasi Prediksi Kelulusan Snmptn). Jurnal, 34. [online], (Diakses 10 Maret 2019).

[8] Wahyuningsih, Y., \& Wibawa, C. S. (2017). Pengembangan Aplikasi Test Online dengan Menggunakan Framework Codeigniter di SMK Darul Ma'Wa Plumpang Pada Mata Pelajaran Jaringan Dasar Kelas X. Jurnal IT-Edu, 2, 36-46. 